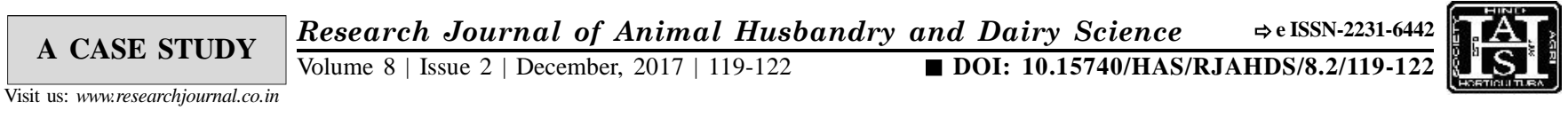

\title{
Backyard poultry farming with improved Giriraja breed
}

\author{
KALYANI W. SARAP
}

\begin{abstract}
A backyard poultry farming based on scientific management practices with high yielding breed of chickens was desired by the rural communities to improve their income. Rural farmers rear Desi type chicken with low egg and meat production in backyard system. For developing the rural poultry farming, improved backyard poultry like Vanaraja, Giriraja birds rearing is of utmost important. Birds can be reared for egg production in small numbers (10-20) in free range conditions if plenty of natural feed resources are available. Chicks need brooding during initial 6 weeks of age to maintain the required body temperature and to protect from predators. At 42 days of age, the birds can be let out under backyard free-range conditions. Birds should be vaccinated specifically against the Newcastle disease and fowl pox. In the primary sector, Agriculture provides about100 to 120 days employment to the rural poor. Scanty land holding, land fragmentation and seasonal agriculture are not able to provide full employment to the work force which in turn creates disguise unemployment. Backyard poultry farming can be a viable option for rural poor to overcome the issue.
\end{abstract}

KEY WORDS : Rural, Backyard poultry, Giriraja

HOW TO CITE THIS PAPER : Sarap, Kalyani W. (2017). Backyard poultry farming with improved Giriraja breed. Res. J. Animal Hus. \& Dairy Sci., 8(2) : 119-122 : DOI: 10.15740/HAS/RJAHDS/8.2/119-122. 